\title{
Access Digital Divide in the Kingdom of Saudi Arabia (KSA): Current State and Measures for Improvement
}

\author{
Altahir Saad \\ Prince Sattam Bin Abdulaziz University /Department of Computer Science, Riyadh, 11912, KSA \\ Email: as.saad@psau.eud.sa \\ Ahmed Fahim \\ Prince Sattam Bin Abdulaziz University /Department of Computer Science, Riyadh, 11912, KSA \\ Email: a.abualeala@psau.edu.sa \\ Faculty of Computers and Information / Department of Computer Science, Suez University, Suez, 43533, Egypt \\ Email: ahmmedfahim@yahoo.com
}

Received: 09 March 2021; Accepted: 03 May 2021; Published: 08 June 2021

\begin{abstract}
In this age the emergence of information and communication technologies (ICTs) has been identified as a major step toward solve the problems challenged the nation development. Problems such as corruption, delays in service delivery, lack of public sector accountability can be overcome with ICT. Furthermore, ICT are the key factors in improving government business and human sustainable development in all life aspects. Whilst the ICT considered the key to these problems but owning these technologies was facing many obstacles staring from bought them to continuous use, and create a gap between countries and within a country from the perspective of who does have computer and networks communication and who doesn't, and this refers to the digital divide. Some aspects of the digital divide exist everywhere and not only related to developing countries but also the size of the gap, which is different in countries and within a single community.

This study focuses on the digital divide problem by exploring the current state of the access digital divide in Kingdom of Saudi Arabia (KSA) based on three main research questions. And to achieve that, Data collected from International Telecommunication Union (ITU), Communications and Information Technology Commission (CITC), and World Bank were used.

The study found that Saudi Arabia is suffering from the access digital divide, and there is a strong link between household income and the access digital divide resulting from unaffordable prices in both ICT and broadband services and this gap tends to be larger in the regions where the inhabitants have the lowest income level.

The study recommends that the government should give improving household income the highest priorities and at the same time offering affordable prices for broadband services. Also, the study finds that mobile penetration represents a valuable resource for the Saudi Arabia government to be investing in delivering government services through mobile platforms. Finally, the study recommends that public-private partnerships with promoting and encouraging the private sectors to invest in ICT is one of the most important measurements in bridging the access digital divide.
\end{abstract}

Index Terms: ICT, Digital divide, Access Digital divide, household income, IDI ranking, KSA

\section{Introduction}

The revolutionary of Information and Communication Technology (ICT) in the 21th century become one of the most transitions in the era of technology and communication. These revolutionaries in ICT become the key factors in improving government business and human sustainable development in all life aspects. The government utilized the ICT for delivering government services, exchange of information, communication transactions, integration of various stand-alone systems and services between government-to-customer (G2C), government-to-business (G2B), government-to-government $(\mathrm{G} 2 \mathrm{G})$ as well as back office processes and the interactions within the entire government framework [1]. With other words, ICT is one of the most important driving forces promoting economic growth and sustainability of any country [2]. 
Furthermore, the covid-19 pandemic was discovered the importance of ICT in delivering government service and conducting many business, where countries with poor ICTs infrastructures or unequal distribution of these assets were tend to be more suffering from the negative economic impacts of this pandemic [3].

Although there are many benefits of ICT for governments, business and individuals but this technology creates a gap or a division between the rich countries that have computers and networks communication and the poor countries that do not have these computers and networks. This gap is called the digital divide.

The term "digital divide" was shed light on by Larry Irving, Jr., former US Assistant Secretary of Commerce for Telecommunication and Communication in the mid-1990s in order to focus public attention on the existing gap in access to information services between those who can afford to purchase the computer hardware and software necessary to participate in the global information network, and low income families and communities who cannot [4].

According to the OECD [5] the concept digital divide can be defined as "the gap between individuals, households, businesses and geographic areas at different socio-economic levels with regard both to their opportunities to access ICTs and to their use of the Internet for a wide variety of activities".

The problem of the digital divide exists everywhere in the world, not only in developing countries but also in the developed countries. According to ITU Report found that in 2019, 81 percent of households in developed countries had Internet access, compared with only 34 percent in developing country regions and 7 percent in the least developed countries. Bridging this gap becomes a top priory in a developed and developing country because ICT plays important role in economic growth, healthy democracy, and economic equality. ICT becomes essential for education and career development [6].

Furthermore, in 2020 the ITU reports show that globally, about 72 percent of households in urban areas had access to the Internet at home in 2019, almost twice as much as in rural areas (nearly 38 percent). Also, the reports found the urban-rural gap was small in developed countries compared to developing countries, and in developing countries, urban access to the Internet was 2.3 times as high as rural access. Moreover, in Africa, the reports found that only 28 percent of households in urban areas had access to the Internet at home, but that was still 4.5 times as high as the percentage in rural areas, which stood at 6.3 percent. In the other regions of the world, household Internet access in urban areas stood between 70 and 88 percent, while access in rural areas ranged between 37 and 78 percent [6].

The purpose of this paper is to review research related to digital divide in general and explore the state of access digital divide problem in the Kingdom of Saudi Arabia (KSA) using data collected from International Telecommunication Union (ITU), Communications and Information Technology Commission (CITC) and World Bank.

Finally, this paper aims to explore an effective measure that can help in bridge or reduce the access digital divide in KSA.

In sum, ICTs have great opportunities to helps governments in delivering their services or conducting business in an efficient manner but the study showed that the prevalence of these technologies was create a gap between countries and within single countries in term of those have ability to buy them or frequently their income guarantee sustainable use. The scope of this study to focus only on exploring the current state of access digital divide in KSA as well as trying to explore the measures that can help in mitigates or reduces the impact of access digital divide problems.

\section{Literature Review}

In this age the emergence of information communication technologies (ICTs) has been identified as a major step toward solve the problem challenged the nation development. Problems such as corruption, delays in service delivery, lack of public sector accountability, and so on, can many believe be overcome with ICT: particularly, the Internet and cell or mobile phones. Whilst the ICT considered the key to these problems but owning these technologies was facing many obstacles staring from bought them to continuous use, and this refers to term called digital divide. Moreover, Selwyn [7], argues the ICT have a great impact and valuable resources in overcoming existing social divisions and inequalities through delivering the government service with an effective and efficient channel and hence increasing transparency and generating a higher degree of trust.

The digital divide phenomena with all dimensions attract the attention of researchers and governments to investigate and tackle the reasons of this phenomena with the aim to discover measurements that can help in reducing the impact of this phenomena.

Acilar [8] explored a digital divide in developing countries with focus on aspects of digital divide in Turkey using Turk-Stat yearly surveys. The study found that the use of computer and internet has significantly increased in turkey over time but still there is a digital divide in the use of computer and internet within turkey, the rate of the use of computer and internet of male resident is higher than that of females. There is a digital divide between Turkey and developed countries. Also, the study found the digital divide between rural and urban areas will likely continue unless problems such as the lower of using computers and the internet in the rural areas are enhancing as well as improving the level of literacy and designing appropriate IT tools for user capabilities.

Stephen [9] presented the status of the digital divide in Africa and the implications for libraries. The study proposed a proposal on how e-governance could be used to narrow the digital divide within libraries in Africa through a 
partnership between libraries and e-government by priorities espoused in e-governance as accessibility affordability, appropriate citizen content, and appropriate conduits are similar to what libraries need to achieve using various ICTs.

Sumanjeet [10] mainly focused on India by exploring the digital divide in rural and urban in the context of teledensity, mobile, and the internet. The study reveals the main obstacles in the rural areas are illiteracy, lack of skills, infrastructure and investment in rural must attract the government attention to put thrust towards connectivity, cost reduction, community participation, core technologies creation and exploitation, competence building, and capacity augmentation would definitely help narrow the gap of the digital divide.

Abu-Shanab and Khasawneh [11] built an instrument to study the digital divide regarding students' perceptions view to measure citizen perceptions toward different types of a digital divide. The study findings indicated that a major consensus was depicted for equal service in rural vs. cities, gender and income level in addition to better public service should be provided to educated people compared to non-educated people. The study recommended future work to validate the instrument and generalize the findings.

Fathiya and George [12] discussed information security and the digital divide in the Arab World using ITU report as a basis to explore the digital divide in the Arab world and seeking to fill the absence of recent sub-skills data. The study concluded that the digital divide is concerned not only with technological issues and material but also with the capabilities of those who use them as a result of the direct relationship between human development and the digital divide. Finally, the study found that the Arab world will face a significant challenge in meeting the requirement of the global marketplace as the overall performance of the information economy in the region may not render the desired result.

Fuchs and Horak [13] studied the phenomenon of the digital divide at the global digital divide concerning Africa using macro-data and discussed specific examples (Ghana, South Africa). The study finding the least developed African countries in terms of income, education, and health have very low Internet access and usage rates. Beyond that, the study demonstrated that neoliberal policies of liberalization, deregulation, and privatization of the telecommunication sector as suggested by the Washington Consensus and Structural Adjustment Programs of institutions like the World Bank and the International Monetary Funds have not succeeded in bridging the digital divide in Africa and the global digital divide because -as an example- in Ghana markets have been extremely liberalized, but the number of Internet users is still very low, whereas poverty and the income gap are high.

Rowena [14] presented a paper that examines the digital divide issues at the national level in the US, UK, Canada, and New Zealand to look for evidence assessing factors that contribute to the digital divide and evaluating strategies that can help reduce it including the role of libraries in reducing the digital divide. The study findings that any addressing to digital divide must take into account Physical access to ICTs, ICT skills and support, Attitudes, and Content as key issues that need much more research and which are not dependent on socio-economic status alone. Also, the study found there is aid money available in most developed countries but to date libraries have not seen themselves as having a role to play in the delivery of development aid to their less well-off colleagues.

Ebbers et al [15] studied the impact of the digital divide on e-government to explore new explanations in channel choice by exploring the citizen's perspective by studying actual channel use in the Netherlands. The study found that although the nature of interaction significantly coheres with channel choice the results show that digital skills do not predict or relate to choosing the online channel, and digital skills do predict the degree of satisfaction i.e. the more digitally skilled citizens are, the more satisfied they are with online services. The study limitation is reliance upon an online survey for data collection and making generalizations to the wider population also study focused only on two sets of digital skills, namely information navigation skills, and mobile skills, and recommend further research could investigate types of digital skills.

Blignaut [16] studied the digital divide in South Africa by focusing on both access and usage digital divide. The study found that South Africa has the largest digital divide between rich and poor and between black and white in both access and usage digital divide. To narrow the digital divide in both dimensions the study proposed a model with two layers; the first layer dealing with soci-economic indicators called the access layer while the second is called the usage layer to deal with usage pattern and gratification user obtain from the internet and other equipment. Finally, the study found that raising the soci-economic standard for the South Africa community has a vital role in narrowing the digital divide gap between both rich and poor and between black and white.

Nwagwu and Ahmed [17] presented and described building open access in Sub -Saharan Africa as an effective measure that can help to close the information divide between developed and developing countries. The study evaluated open access as means of accessing scientific knowledge in South Africa and proposed open access initiatives that need to carry out to narrowing the knowledge divide in Sub -Saharan Africa.

De Beer [18] studied the impact of knowledge and access to technology as key factors to Africa's future. The study found that addressing the technological digital divide alone will not be enough in addressing the digital divide and must be connected with the human divide. Also, the study proposed the creation of groups of contagious intelligence will be far more productive in the long term than focusing on individual's intelligence.

Ahmed [19] presented a paper that aimed to examine whether Open Access is an effective solution for bridging the digital divide in Africa. The study presented the literature review related to ICTs and the digital divide in developing countries using the Digital Opportunity Index (DOI). Also, the study found that while open access would be beneficial 
in developing countries there still challenges and threats facing open access in Africa. To reduce this economic value; training users and developers, and policy support open access could be key factors to success open access in bridge the digital divide in Africa.

People with low income may face challenges to owning ICT due to high cost compared with their incomes , moreover in terms of ICT costs and prices, also these factors are considered an important aspect related to the access of internet, for instance Mann et al[20] found that the higher internet subscription charges affect its access negatively, and caused the digital divide.

On the other hand, Frank and Kwaku [21] presented a study focusing on Ghana's to examine the government's attempt to address digital divide problem including how the problem has been defined, the steps that are being taken to heal it, the implied challenges, if any, facing the government, and how it can address these challenges. Furthermore the study found addressing regulatory issues consider an area of great concern especially relating to private sector involvement, and governments must reforms regularities and policy to achievie competitive measures to stimulate digital expansion nationwide as well as encourage the private sector to focus on the development of access and value added services to benefit the rural areas by initiate policy interventions in the form of incentives that will include tax breaks for private sector organizations, who may wish to promote access and inclusiveness solutions to benefit the communities in underserved areas.

\section{Resarch Questions}

The global digital divide refers to differences between countries in terms of access to ICTs. ICT access inequality is called the first-order digital divide and ICT use inequality is called the second-order digital divide [22]. This paper focuses on the bridge Access digital divide related to the questions below:

- RQ1: What is the relation between people's income and the Access digital divide: Several factors make it difficult for people to obtain access to ICT but income level is a key barrier to internet access, and internet penetration is often the lowest in countries with the lowest GDP per capita and unless these individuals can utilize free or cheap products, they won't be able to gain the benefits of the technology revolution [23].

- RQ2: What are the most effective measures to bridge the Access digital divide in KSA: Access digital divide is not identical in countries and there exist many measures to consider, but determining the most effective measures is very important because regions differ in many elements such as the size of the divide, economic, population density, etc. Therefore, no single measure or solution is fitting all countries.

- RQ3: How to promote the private sector to deal with the Access digital divide: Closing or bridging access digital divide is huge work especially in a developing country that has limited resources and expenditure on many issues hence promoting and engaging the private sector to deal with bridging the access digital divide can reduce the burden on the government to face this problem.

\section{Resarch Methodolgy}

The concept of the digital divide has many dimensions but this paper focuses on the Access digital divide in Saudi Arabia. This paper tries to explore the current state of access digital divide within KSA using the data collected from the World Bank that will be used to answer the first question. While data collected from both ITU and CITC are used to answer the second and third questions.

Besides answering the research question, this paper aims firstly to explore the access digital divide in the Kingdom of Saudi Arabia (KSA) and then explore the most effective measures to bridge the Access digital divide in KSA.

In sum, the data offered by the World Bank represent a great help in understanding the nature of the KSA economic and the levels of incomes between the population and how these incomes reflection on owning or use ICTs , while the rich amount of data gathered from both ITU and CITC can be used to understand and explore the current situation of KSA regarding the ICTs capabilities where these reports include a massive documentation for ICT Development Index (IDI) which represent a benchmark measure that can be used to monitor and compare developments in information and communication technology (ICT) between countries and over time.

\section{Access Digital Divide in KSA}

The studies showed that the digital divide has many dimensions and measuring the digital divide it depends on which type of divide is measured and which methods are used. This section aims to explore the Access digital divide in Saudi Arabia using the ICT development index (IDI) ranking provided by the International telecommunication Union combined with Saudi Communications and Information Technology Commission data.

The ICT Development Index (IDI) is a composite index that combines 11 indicators into one benchmark measure that can be used to monitor and compare developments in information and communication technology (ICT) between countries and over time. The 11 indicators include five indicators called Access sub-index that are used to measure ICT 
readiness. These indicators are fixed telephone subscriptions, mobile-cellular telephone subscriptions, and international Internet bandwidth per Internet user, households with a computer, and households with Internet access [24].

Kingdom of Saudi Arabia is an oil county in the Middle East with a population of around 34 million capita with a growth rate of $1.59 \%$ and population density of 16 capita per $\mathrm{km}^{2}$. The rate of urban population is around $84 \%$ compared with $16 \%$ as rate of the rural population (World Bank 2020 and Saudi Arabia General Authority for Statistic).

In 2019, the economy of Saudi Arabia -as a Gross domestic product- ranked at 18th with 23139.8 USD GDP per capita (World Bank 2020) while is estimated to be ranked at 19th as in the international monetary fund (IMF) report.

The IDI ranking data showed that 86.2 percentages of households have computers compared with 13.8 percentages of households without a computer and most of them living in rural areas with limited income and lack of desire to owning a computer [24].

The IDI ranking reveals that although 99 percent of households with a computer have internet access, only 95.7 percent of these households use the Internet due to two main reasons; lack of skills and high cost of the Internet subscription compared with level income [24]. Also, the IDI ranking data show that Fixed-telephone subscriptions per 100 inhabitants are 15.69 while Mobile-cellular telephone subscriptions per 100 inhabitants are 120.5 due to the competition of the mobile services in prices and variety of offerings which make it a substitution of fixed services for some of the Users [24]. In Broadband subscriptions, the IDI data show that Fixed (wired)-broadband subscriptions per 100 inhabitants are 19.85 while mobile-broadband subscriptions per 100 inhabitants are 116.88 [24].

Finally, the number of Internet users has increased rapidly in the last years whereas it reaches 95.72 percentages by the end of 2019 with 9836653 International internet bandwidth per Internet user (Bit/s) [24]. The detailed IDI ranking of Saudi Arabia related to the Access sub-index is presented in Table 1.

Table 1. IDI Access sub-index Indicators of Saudi Arabia in 2019 [6].

\begin{tabular}{|c|c|}
\hline Indicators & 2019 \\
\hline Fixed-telephone subscriptions per 100 inhabitants & 15.69 \\
\hline Mobile-cellular telephone subscriptions per 100 inhabitants & 120.5 \\
\hline International internet bandwidth per Internet user (Bit/s) & 9836653 \\
\hline Percentage of households with computer & 86.2 \\
\hline Percentage of households with Internet access & 99 \\
\hline Percentage of individuals using the Internet & 95.7 \\
\hline Fixed (wired)-broadband subscriptions per 100 inhabitants & 19.85 \\
\hline Active mobile-broadband subscriptions per 100 inhabitants & 116.88 \\
\hline
\end{tabular}

According to CITC [20] the main reason for the drop in IDI ranking in 2019 due to: -

- Connecting mobile number with a fingerprint.

- Change in user needs and technology as a result of competition between mobile broadband and wired broadband.

- Lack of internet service provider.

- Limited affordable internet price especially within areas of lower-income.

- The CITC expected the decrease in internet and mobile subscriptions to continue in the upcoming period especially in rural areas with lower income.

From previous information, we conclude that Saudi Arabia suffering from access digital divide as most developing countries but the good indicators announced in the 2030 vision of Saudi Arabia by taken the digital divide problem the highest priority, besides improving people income in the rural areas and encouraging to provide affordable prices to access ICT.

\section{Most Effective Measuers to Bridge Access Digital Divide in KSA}

As explained in the previous section Saudi Arabia and most developing countries suffering from the Access digital divide problem. In this section, we are trying to explore the most effective measures that can help in narrowing or bridging the Access digital divide in KSA. Although they are many elements that can helps in birding this gap as well as these elements are tightly coupled with countries nature, population and etc...., and in this study we recommended the elements below based on KSA's "vision 2030" which have many targets, and addressing needs, challenge and opportunities of telecommunication sectors one of them as well as trying to achieves Sustainable Development Goal (SDGs) relevant to ICT have a direct impact on narrowing or eliminating this problem. In sum, the elements below extracted from both KSA's "vision 2030" and SDGs. 


\subsection{Improving households Income}

Although Saudi Arabia has huge oil reserves, household income is around \$3,957 per month, and the unemployment rate is $\mathbf{1 2 . 6}$ percent and studies show that most barriers to owning and use ICT in rural areas as general resulting from the lower level of income and education, hence setting policy for improving the income level of Saudi Arabia people in rural areas is a big chance to promote this category to owning and use ICT (General Authority for Statistic KSA, 2021),[25].

\subsection{Affordable Broadband Price}

In addition to the high cost of ICT, the Unaffordable broadband price remains one of the key barriers to ICT uptake and leads to excluding many people from the global information society [19]. Fixed-broadband in Saudi Arabia costs around 67.16 USD with unlimited data and speed of $60 \mathrm{MB} / \mathrm{s}$. Mobile broadband for $1 \mathrm{~GB}$ costs around 9 USD per month. Comparing the price of broadband for both fixed and mobile with GDP per capita around 23,139 USD is considered to be Unaffordable especially for people who have lower income. The IDI data show that 99 percentage of households already with Internet access but only 95.7 percentage of individuals using the Internet, therefore, offering an affordable price for internet broadband for both wired and mobile has a direct impact on increasing the number of households using the internet [24].

\subsection{Mobile-Government}

Mobile penetration represents 120.5 mobile-cellular telephone subscriptions per 100 inhabitants, in addition to 116.88 Active mobile-broadband subscriptions per 100 inhabitants hence with offering affordable mobile broadband prices and delivering government service through a mobile platform is feasible and has a great impact on closing this gap especially for people in rural area [24].

\subsection{Public Library and Academic Institutions}

Public libraries and academic institutions can play a vital role in bridging the access digital divide especially for those with lower income levels by providing free access to computers and Internet services to people suffering from obtaining and using this resource. Beyond that, public libraries and academic institutions can arrange for training uneducated people to develop their skills to use ICT. This effort can lead to participation in closing the skill digital divide. Although Saudi Arabia has 34 government universities most of them exist in or cover the urban areas. Public libraries suffer from a lack of preparation, they are in large cities only, and therefore this measure without increasing penetration for rural areas becomes unfeasible.

\subsection{Public-Private Partnerships}

Public-Private Partnerships (PPPs) are co-operation between public and private actors for developing products and/or services, sharing risks, costs, and benefits, and based on the idea of mutual added value [26]. Economic of Saudi Arabia depends on oil revenues but after the economic crisis the oil prices are not stable and these changes directly affect all government projects budget. Closing access digital divide is a challenging task especially for a government with a limited budget and revenues and expenditure for different issues. In this situation, public-private partnership has a significant role in closing this gap through promoting the private sector to investing in extend and establish ICT infrastructures with fair market competition.

In June 2015, the Saudi Arabia government announced "Saudi Arabia's Vision 2030" where the economy will be based on partnerships between public and private sectors through removing barriers and stimulating the private sector.

In closing the access digital divide the Vision planned to Increase penetration of high-speed broadband access by promoting investment in Fiber optic roll-out in Saudi Arabia to achieve 80\% coverage in densely populated urban areas and 55\% in other urban zones by 2020 (Saudi Arabia's Vision 2030).

\subsection{Citizen Engagement}

Engaging citizens with true participation in decision-making and discussing issue related to access digital divide such as employment and investing in rural areas has a vital role in eliminating or narrowing this problem because dealing with citizen necessary humanities service like improving households income, water, electricity, ..., etc. are great chance to promote and increase ICT uptake [27].

\section{Results}

The digital divide with all aspects exists everywhere and is not just related to developing countries but also to the size of the gap, which is different in countries and within a single community.

The annual reports distributed by the World Bank institute was helped us to get clear picture about the nature of the KSA economic and the levels of incomes between the population and how these incomes reflection on owning or use ICTs , while the rich amount of data collected from both ITU and CITC was used to understand and explore the 
current situation of KSA regarding the ICTs capabilities where these reports include a massive documentation for ICT Development Index (IDI) which represent a benchmark measure that can be used to monitor and compare developments in information and communication technology (ICT) between countries and over time.

As we illustrated early based on the data of the General Authority for Statistic KSA the incomes level for an individual and the rate of unemployment are consider the main challenge facing owning and use ICT especially in rural areas and the height cost of these technology add another dimension that may expand the access digital divide but the good sound the government was lanced a program aims to decrease the rate of unemployment by replacing many jobs running by forging or non-Saudi to be fill by Saudi citizens as well as customized an Citizen account support with approximately $100 \$$ per month for the individual. These efforts to decrease the rate of the employment and improve the income level have a great impact to help in closing the gap of the access digital divide.

In developing countries, for instance, millions of dollars are customized to be funded and expended on programs and projects to address the digital divide problems, particularly in rural areas, where poverty and disease are most widespread. Saudi Arabia has not been left behind these efforts in the drive to use ICT for development where the Saudi "2030 vision" set many objectives regarding the ICT development and measures to mitigate the impacts of digital divide and access digital divide in specifics.

Furthermore, the government is always revised the policy related to telecommunication sector not only to support closing the gap of digital divide but also support the government budget, and reports showed the communications and information technology sector contributes up to $5.5 \%$ of the Kingdom's GDP and the size of the telecommunications market in the Kingdom was estimated at 70 billion riyals, the size of the information technology market at 64 billion riyals, and the size of the postal market at 6.4 billion riyals[25].

On the other hand, the policy of the digital economy in the Kingdom has contributed to attracting global partnerships to the Kingdom with huge investments, and a digital government body has recently been launched in the Kingdom that will lead the Kingdom in the future to ensure the government digital transformation and ensure that it works as required. In sum, partnership between government and private sector specially telecommunication can play significant role in closing this gap through promoting the private sector to investing in extend and establish ICT infrastructures with fair market competition.

Finally, most service provided by the government delivered through electronic channel such as the web, mobile Apps and ATM, so the government have a great chance if they succeed in made these service consumed with mobile app without fees or the telecommunication company provided them for free as social responsibility particularly for those lack from the high cost of internet or broadband .The idea was implemented during covid-19 pandemic by most telecommunication operators for the elementary school by making surfing the youtube channel broadcasting the schools content free.

In sum, Saudi Arabia suffering from the Access digital divide despite the government effort to narrowing this gap technologically. This study found that there is a strong link between household's income and Access digital divide resulting from unaffordable prices in both ICT and -broadband services and this gap tends to be more effecting population or regions that has the lowest income level.

While the government is trying to address the access digital divide in both rural and urban areas with different policies. The study recommends that the most effective measurement to narrow this gap must take improving households income highest priorities and at the same time offering affordable prices for broadband services. Also, the study finds that mobile penetration represents a valuable resource for the Saudi Arabia government to be investing in delivering government services through mobile platforms. Finally, the study finds and recommends that public-private partnerships with promoting and encouraging the private sectors to invest in ICT become one of the most important measurements in bridging the access digital divide.

\section{Discussion}

During the exploration and conducting this research there are many lessons learned related to the phenomena of the digital divide in general and the efforts carried out to narrow this gap, the lessons learned can be determined below: -

- Lesson \# 1: Before doing this research, we heard much about ranking index but knowing how this ranking calculated is considered big lesson from this paper.

- Lesson \# 2: The digital divide is concerned not only with technological issues but also strongly connected with development goals and any failure in these goals has direct impacts on all digital divide aspects not only access digital divide.

- Lesson \# 3: The phenomena of the digital divide have many dimensions and existing everywhere but treating and perception about this phenomenon in developed courtiers are priorities as human's rights comparing with luxury in developing courtiers.

- Lesson \# 4: Bridging access digital divide is a huge effort that requires participation from all community members and this phenomenon is not only a government problem. 
- Lesson \# 5: The ICT development index (IDI) provides a lot of information that could be invested in setting and revising the ICT field.

- Lesson \# 6: The digital divide problem is a phenomenon that may not be new but its impacts and treatment has dynamically changed over the time.

\section{Conclusion}

The revolution in ICT has become a key factor in improving government business and human sustainable development in all life aspects but most developing countries have not been able to access the ICT for obtaining the benefits of this revolution. The inability to access the ICT between countries and individuals is called the digital divide.

In this study we firstly illustrated the concept of digital divide, which has become an international matter and discussed daily by the stakeholders nationally and locally. In this study, the authors are focused on exploring the current state of the access digital divide in the divide in the Kingdom of Saudi Arabia (KSA), and not between KSA and the international community. Also we suggested some measurements that we believe can be used by the government and private sectors to address this problem.

Because bridging this gap plays important role in economic growth, healthy democracy, and Economic equality and becomes essential for education and career development. This paper explores the access digital divide in the Kingdom of Saudi Arabia and examines the most effective measurements to bridge the access digital divide.

The KSA government continuously seeking to initiate and implement programs and projects to address the problem and these efforts was noted in the "2030 vision" which for instance the government and private sectors are obligated to deliver their service to customer through electronic channel. Although this tangible efforts, much more needs to be done if the government is to close the gap between the urban and rural areas. And to achieve reform the policy and regulations continuously must be discussed with all stakeholder as well as provide incentives for private sector to increase their investments in the ICTs.

In sum, the limitation of this study is only focusing on access digital divide in the Kingdom of Saudi Arabia with data collected from reports issued by the International Telecommunication Union (ITU), Communications and Information Technology Commission (CITC), and World Bank.

Exploring and addressing the digital divide with all dimensions or the access digital divide with the other data ranking indexes for measuring information society would be the future work.

\section{Acknowledgment}

The authors would like to thank Dr. Nizar Omer Associate Professor, College of Sciences and Humanities- Aflaj, for his support and effort to explain terms and concepts related to World Bank and sustainable development.

\section{References}

[1] T. Janowski, "Digital Government Principles , Practice and Research Module 1 : Introduction to Digital Government," pp. 1-42, 2015.

[2] Mahbobor Rahaman, "Addiction of Information and Communication Technology (ICT) and Internet by the Bangladeshi University Students and Its Impact on Their Future", International Journal of Information Technology and Computer Science(IJITCS), Vol.10, No.8, pp.56-68, 2018. DOI: 10.5815/ijitcs.2018.08.08

[3] Milena Bogdanović,"Growing Importance of Distance Education", International Journal of Modern Education and Computer Science (IJMECS), vol.4, no.3, pp.35-41, 2012.

[4] C. Boje and N.-G. Dragulanescu, "'Digital divide' in Eastern European countries and its social impact," ASEE Annu. Conf. Proc., pp. 9047-9060, 2003.

[5] OECD, "Understanding the Digital Divide," Ind. Law J., vol. 6, no. 1, pp. 52-54, 2001.

[6] UIT, "Measuring digital development. Facts and figures 2020," ITU Publ., pp. 1-15, 2020, [Online]. Available: https://www.itu.int/en/mediacentre/Documents/MediaRelations/ITU Facts and Figures 2019 - Embargoed 5 November 1200 CET.pdf.

[7] Selwyn, Neil. "'E-stablishing'an inclusive society? Technology, social exclusion and UK government policy making." Journal of social Policy 31 (2002): 1.

[8] A. Acilar, "Exploring the aspects of digital divide in a developing country," Issues Informing Sci. Inf. Technol., vol. 8, pp. 231-244, 2011.

[9] S. M. Mutula, "Bridging the digital divide through e - governance," Electron. Libr., vol. 23, no. 5, pp. 591-602, 2005.

[10] S. Singh, "Digital Divide in India: Measurement, Determinants and Policy for Adressing the Challenges in Bridging Digital Divide,” Thinkers Writ. Forum / Compend. Pap. 2009-10, pp. 124-136, 2009.

[11] E. Abu-shanab and R. Khasawneh, "E-Government Adoption : a Digital Divide Perceptional View," Int. Conf. Inf. Technol., vol. 6, 2013.

[12] F. Al Izki and G. R. S. Weir, "Information Security and Digital Divide in the Arab World," pp. 15-24, 2014.

[13] C. Fuchs and E. Horak, "Africa and the digital divide," Telemat. Informatics, vol. 25, no. 2, pp. 99-116, 2008.

[14] R. Cullen, “Addressing the digital divide,” Online Inf. Rev., vol. 25, no. 5, pp. 311-320, 2001. 
[15] W. E. Ebbers, M. G. M. Jansen, and A. J. A. M. van Deursen, "Impact of the digital divide on e-government: Expanding from channel choice to channel usage," Gov. Inf. Q., vol. 33, no. 4, pp. 685-692, 2015.

[16] P. Blignaut, "A Bilateral Perspective on the Digital Divide in South Africa," Perspect. Glob. Dev. Technol., vol. 8, no. April, pp. 581-601, 2009.

[17] W. E. Nwagwu and A. Ahmed, "Building open access in Africa," Int. J. Technol. Manag., vol. 45, no. 1-2, pp. 82-101, 2009.

[18] C. De Beer and C. S. De Beer, "Africa in the globalising world: digital divide or human divide?," Communicatio, vol. 33, no. 2, pp. 196-207, 2007.

[19] A. Ahmed, "Open Access Towards Bridging the Digital Divide-Policies and Strategies for Developing Countries," Inf. Technol. Dev., vol. 15, no. 1, pp. 43-51, 2009.

[20] Mann, Catherine L., Sue E. Eckert, and Sarah Cleeland Knight. Global electronic commerce: A policy primer. Peterson Institute, 2000.

[21] Ohemeng, Frank Louis Kwaku, and Kwaku Ofosu-Adarkwa. "Overcoming the digital divide in developing countries: An examination of Ghana's strategies to promote universal access to information communication technologies (ICTs)." Journal of Developing Societies 30.3 (2014): 297-322.

[22] J. Jin and A. W. H. Cheong, "Measuring Digital Divide: The Exploration in Macao,” Obs., vol. 2, pp. 259-272, 2008.

[23] D. M. West, "Digital Divide: Improving Internet Access In The Developing World Through Affordable Services And Diverse Content Executive Summery," Cent. Technol. Innov. Brookings, no. February, pp. 1-30, 2015.

[24] ITU. 2021. Statistics. [online] Available at: <https://www.itu.int/en/ITU-D/Statistics/Pages/stat/default.aspx> [Accessed 6 April 2021].

[25] C. C. Citc and S. A. Citc, "KSA ICT Indicators End of Q3 2016 The ICT Sector growth in the Kingdom of Saudi Arabia 1Mobile Telecommunications Market," 2016.

[26] T. Janowski, "Digital Government Principles , Practice and Research Module 4: Digital Government Infrastructure and Services," 2015.

[27] T. Janowski and E. Estevez, "Digital Government Principles , Practice and Research and Electronic Participation,” 2015.

\section{Authors' Profiles}

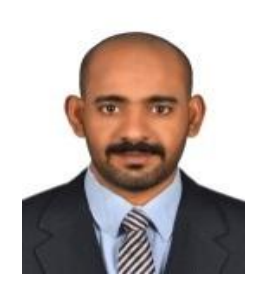

Altahir S. Saad was born in Jan 1986, Aljazerra state, Sudan, got his B.Sc. and PhD in computer science from College of Computer Science and Information Technology, Sudan University of Science and Technology (SUST) in 2010 and 2019 Respectively while his got master degree in computer science from University of Khartoum, College of Science in 2013. He currently works as a Lecturer at the prince Sattam Bin Abdulaziz University, KSA. He is interested in service design, $\mathrm{CSCW}$, and he has publish and conducting his $\mathrm{PhD}$ in this field.

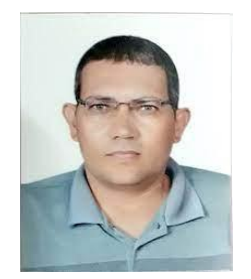

Ahmed M. Fahim was born in December 1976, Menofia, Egypt, got his B.Sc. in computer science from Faculty of Science, Menofia University in 1998, and PhD. in 2010, and he works at Faculty of computers and information, Suez University, Suez, Egypt. Now, he is working at prince Sattam Bin Abdulaziz University, KSA. $\mathrm{He}$ is interested in data mining and knowledge discovery, and has published some research papers in different international journals and conferences.

How to cite this paper: Altahir Saad, Ahmed Fahim, " Access Digital Divide in the Kingdom of Saudi Arabia (KSA): Current State and Measures for Improvement ", International Journal of Information Engineering and Electronic Business(IJIEEB), Vol.13, No.3, pp. 13-21, 2021. DOI: 10.5815/ijieeb.2021.03.02 